\title{
EQUIPAMENTOS DE PROTEÇÃO INDIVIDUAL (EPI) NA COLHEITA MANUAL DE CITRUS
}

\section{PERSONAL PROTECTIVE EQUIPMENT (PPE) IN MANUAL HARVESTING OF CITRUS}

\author{
Roger Weber Escudeiro - roger-escudeiro@ hotmail.com \\ Daniela Rodolpho - danirodolpho@yahoo.com.br \\ Faculdade de Tecnologia de Taquaritinga (FATEC) - SP - Brasil
}

DOI: 10.31510/infa.v15i1.332

\section{RESUMO}

O objetivo desse trabalho é expor todos os equipamentos de proteção individual que um trabalhador deve utilizar na colheita manual de citrus e suas funcionalidades, destacando que com estes a probabilidade de ocasionar um acidente ou uma doença ocupacional é expressivamente menor. Esse tipo de colheita gera muito desconforto físico aos funcionários e os submetem a um alto risco de acidentes, risco esse que é potencializado na ausência ou no uso incorreto dos EPI's. Cabe salientar que é dever do empregador fornecer e fiscalizar a entrega dos equipamentos de segurança ao empregado e é de obrigação do empregado utilizálo apenas para a finalidade a que se destina e responsabilizar-se pela guarda e conservação do mesmo assim determinado pelas Normas Regulamentadoras do Ministério do trabalho. Com a utilização dos equipamentos o trabalhador poderá desenvolver sua função com mais segurança, sendo capaz de ter uma produção maior sem se expor ao acidente de trabalho.

Palavras-chave: Citricultura; Colheita manual; Equipamentos de Proteção Individual.

\begin{abstract}
The objective of this work is to expose all the personal protection equipment that a worker must use the manual harvest of citrus and its features, noting that with these the probability cause an accident or an occupational disease is significantly smaller. This type of collection generates very physical discomfort to employees and submit to a high risk of accidents, risk that is heightened in the absence or in the incorrect use of PPE's. stress that it is the duty of the employer to provide and supervise the delivery of safety equipment to the employee and the employee's obligation is to use it only for the purpose for which it is intended and be responsible for the custody and preservation of the still determined by the regulatory norms of the Ministry of labour. With the use of equipment a worker can develop your function with more security, being able to have a bigger production without exposing yourself to an accident at work.
\end{abstract}

Keywords: Citriculture; Manual harvesting; Equipments for individual safety. 


\section{INTRODUÇÃO}

A citricultura brasileira ocupa lugar de destaque no mercado internacional, com grande representatividade econômica e social na geração de divisas e empregos no país. Nas últimas décadas, o setor vem se alterando por razões conjunturais, com reflexos no processo de colheita. Neste contexto, a mecanização deste processo se difunde como alternativa possível para redução de custos e aumento de produtividade. Entretanto, a implantação destas novas tecnologias nos pomares brasileiros carece de análise do ponto de vista da saúde e produtividade, em contraponto ao uso consolidado da colheita manual (COSTA, 2003).

A colheita manual é uma atividade que causa grande desconforto físico e consequentemente se agravado poderá ocasionar um acidente de trabalho, que segundo Costa (2003), as regiões mais afetadas do corpo são o ombro, a coluna e os membros inferiores. Há também outras regiões que são afetadas como as mãos, braços, olhos e pele.

A legislação brasileira, por meio da Lei $\mathrm{n}^{\circ}$ 8.213/91 em seu artigo 19 define acidente de trabalho da seguinte forma: "é o que ocorre pelo exercício do trabalho a serviço da empresa (...) provocando lesão corporal ou perturbação funcional que cause a morte ou a perda ou redução, permanente ou temporária, da capacidade para o trabalho". Nesse contexto se faz necessário o uso dos EPI's nos ambientes onde a colheita de citrus é realizada.

Para Ramos (2009), esses EPI's são destinados a proteger a integridade física e preservar a saúde do trabalhador. Nascimento et al. (2009) afirmam que os EPI's formam, em conjunto, um recurso amplamente utilizado para a segurança do trabalhador no exercício de suas funções. Assumem, por essa razão, papel de grande responsabilidade para a preservação do trabalhador contra os mais variados riscos aos quais está sujeito nos ambientes de trabalho.

O objetivo desse estudo é fornecer informações sobre as responsabilidades do empregador e as do empregado em relação aos Equipamentos de Proteção Individual (EPI), serão apresentados também todos os equipamentos a serem usados na colheita. Visando ressaltar que o uso dos EPIs resulta na melhoria no quesito prevenção de acidentes e saúde ocupacional, gerando assim menos custos ao empregador e uma segurança maior ao trabalhador ao realizar sua atividade laboral. 


\section{WTEERFAET TECNOLLGGCA}

\section{MATERIAL E MÉTODOS}

Para a elaboração desse artigo foram realizadas pesquisas bibliográficas, a partir do levantamento de referências teóricas já publicadas por meios escritos e eletrônicos, como livros, artigos científicos e páginas de websites.

A pesquisa foi desenvolvida e facilitada devido a experiência profissional e técnica nas áreas de segurança do trabalho e da colheita manual de citrus pelo próprio autor deste artigo.

\section{COLHEITA MANUAL DE CITRUS}

As culturas de citrus são perenes, sendo assim, elas dão frutos nas estações propícias para sua melhor produção. Com isso os funcionários são safristas, trabalham entre 3 até 7 meses no ano, dependendo da cultura de citrus especifica .

A jornada de trabalho dos colhedores inicia geralmente às $7 \mathrm{~h} 30$ da manhã, com a colocação dos EPIs, estes têm em sua rotina o trabalho de subir nas escadas e colher as laranjas das árvores, que são colocadas em sacolas penduradas ao corpo. Quando a sacola fica cheia, as laranjas são colocadas em um saco maior, apontado ao final do dia por um fiscal. O perfil dos colhedores de laranja é composto, em sua maioria, por homens com idade entre $30 \mathrm{e}$ 49 anos, com ensino fundamental incompleto, e com remuneração entre um e dois salários mínimos, dependendo da produtividade.

\section{ACIDENTES NA COLHEITA}

O acidente de trabalho além de representar um custo elevado em tratamento médico, indenizações, perdas de produção, atrasos, trazem graves problemas ao acidentado e à sua família. No meio rural, para a infelicidade de muitos, se concentram uma alta taxa de trabalhadores sem registro na carteira de trabalho e, portanto, desassistidos pelos órgãos de assistência social e saúde pública.

$\mathrm{Na}$ atividade de colheita manual há vários fatores que deve-se levar em consideração sobre acidentes de trabalho, fatores como por exemplo: clima, treinamento do funcionário, fornecimento de EPI, atos inseguros. Um colhedor de citrus está suscetível a sofrer acidentes diariamente. Por ser uma atividade manual, o trabalhador submete-se a um esforço utilizando os membros superiores e inferiores, em movimentos repetitivos durante várias horas por dia. 


\section{EQUIPAMENTOS DE PROTEÇÃO INDIVUDAL}

Segundo a Norma Regulamentadora 6 - NR 6 (1978) considera-se Equipamento de Proteção Individual - EPI, todo dispositivo ou produto, de uso individual utilizado pelo trabalhador, destinado à proteção de riscos suscetíveis de ameaçar a segurança e a saúde no trabalho. O uso do EPI nasceu legalmente falando da CLT (Consolidação das Leis do Trabalho) por meio do Decreto Lei $\mathrm{N}^{\circ} 5.452$ de $1^{\circ}$ de Maio de 1943, em seu artigo 160 foi determinado que em todas as atividades exigidas o empregador forneceria o EPI.

A empresa é obrigada a fornecer ao empregado o EPI adequado ao risco em que esse está exposto, deve fornecer também os equipamentos em perfeito estado de conservação e funcionamento sem cobrar absolutamente nada do trabalhador.

Segundo a NR 6 (1978) cabe ao empregador e ao empregado quanto ao EPI:

Empregador:

a) adquirir o adequado ao risco de cada atividade;

b) exigir seu uso;

c) fornecer ao trabalhador somente o aprovado pelo órgão nacional competente em matéria de segurança e saúde no trabalho;

d) orientar e treinar o trabalhador sobre o uso adequado, guarda e conservação;

e) substituir imediatamente, quando danificado ou extraviado;

f) responsabilizar-se pela higienização e manutenção periódica; e,

g) comunicar ao MTE qualquer irregularidade observada.

h) registrar o seu fornecimento ao trabalhador, podendo ser adotados livros, fichas ou sistema eletrônico.

Empregado:

a) usar, utilizando-o apenas para a finalidade a que se destina;

b) responsabilizar-se pela guarda e conservação;

c) comunicar ao empregador qualquer alteração que o torne impróprio para uso; e,

d) cumprir as determinações do empregador sobre o uso adequado 


\section{EQUIPAMENTOS DE PROTEÇÃO INDIVIDUAL PARA COLHEITA MANUAL}

Os equipamentos de proteção individual devem ser mantidos em boas condições de uso, e precisam ter um Certificado de Aprovação do órgão competente para garantir que estão em conformidade com as determinações do Ministério do Trabalho. Empregados e empregadores devem compreender a importância do uso de equipamentos de proteção no dia a dia da colheita.

Segundo o MTE (Ministério do Trabalho e Emprego, Portaria 3.214 de 08 de Junho de 1978) - juntamente com a NR 6 e Norma Regulamentadora 31 - NR 31 os Equipamentos de proteção individual de um colhedor de citrus são os seguintes:

\section{Ilustração 1- Touca Árabe}
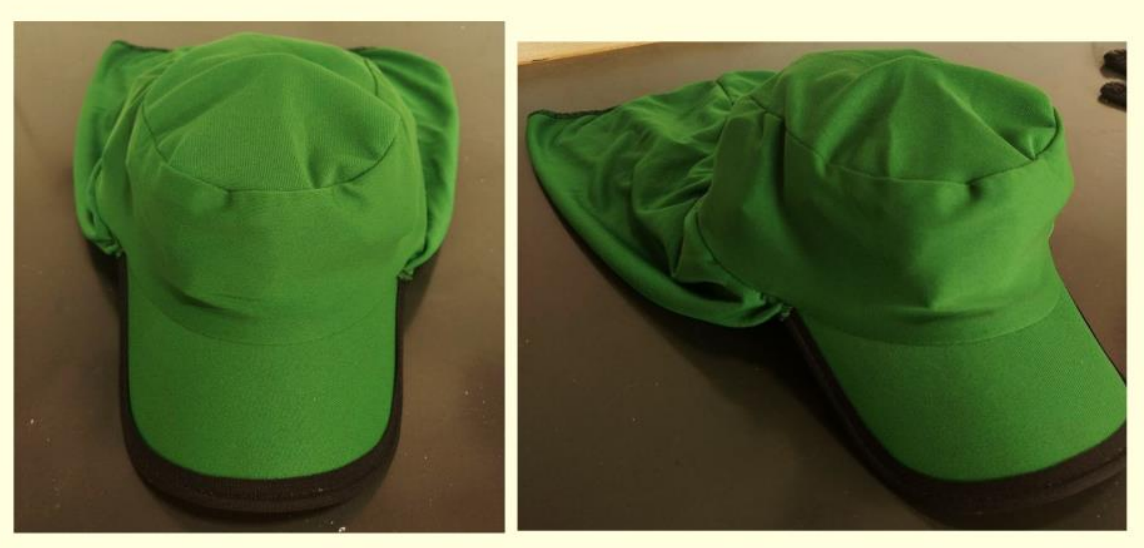

Fonte : Elaborado pelo autor (2018)

A touca árabe geralmente é confeccionada de malha dupla de poliéster com um fechamento na frente por meio de um velcro. Sua finalidade é proteger o trabalhador dos raios solares na região da nuca e da face. 


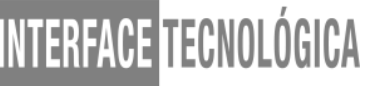

Ilustração 2 - Óculos de proteção

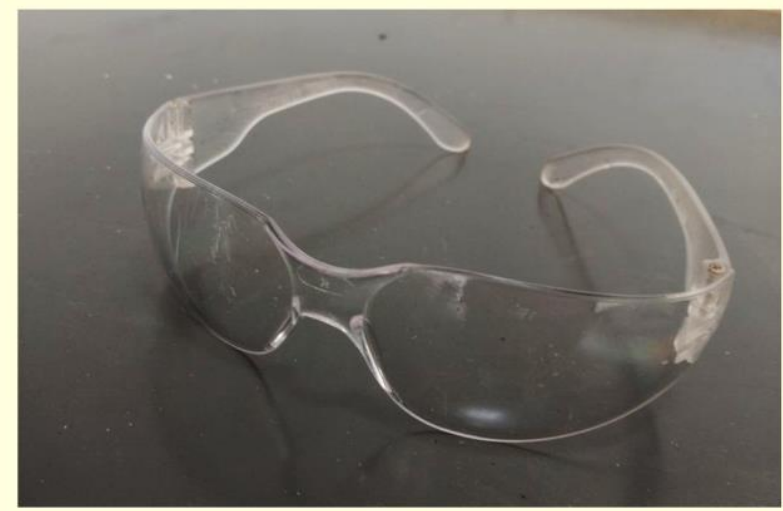

Fonte: Elaborado pelo autor (2018)

Os óculos de proteção geralmente são confeccionados de plástico incolor, possuem hastes flexíveis e proteção lateral. Sua finalidade é a proteção do globo ocular de objetos estranhos, poeira, produtos químicos.

\section{Ilustração 3 - Avental com mangas longas}

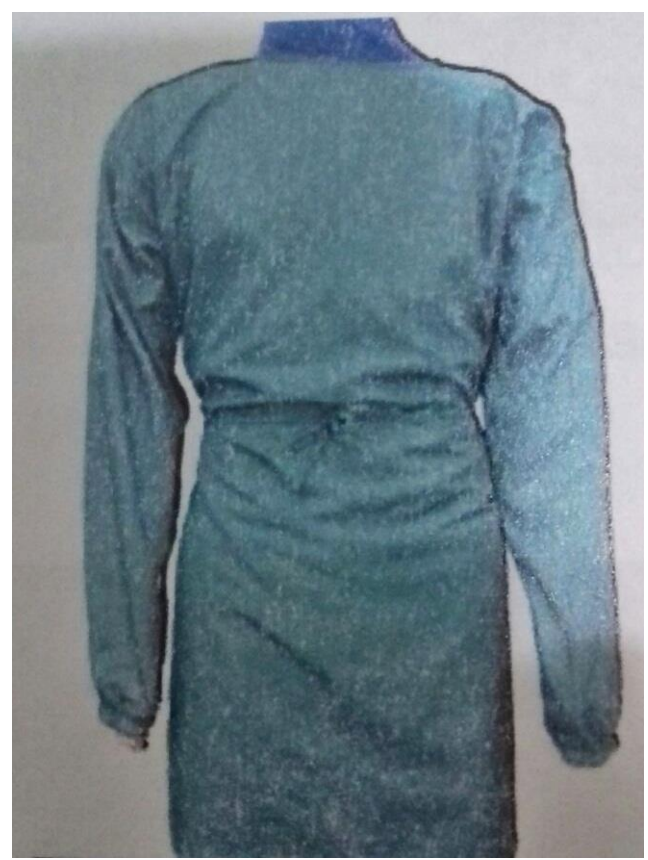

Fonte: Bussadori (2009)

O avental é confeccionado geralmente de pano mais grosso. Sua finalidade é a proteção dos membros superiores e peitoral dos raios solares, e também a proteção de pequenos arranhões devido aos galhos da cultura. 


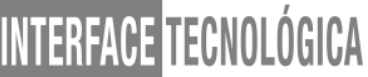

Ilustração 4 - Perneiras ou Caneleiras

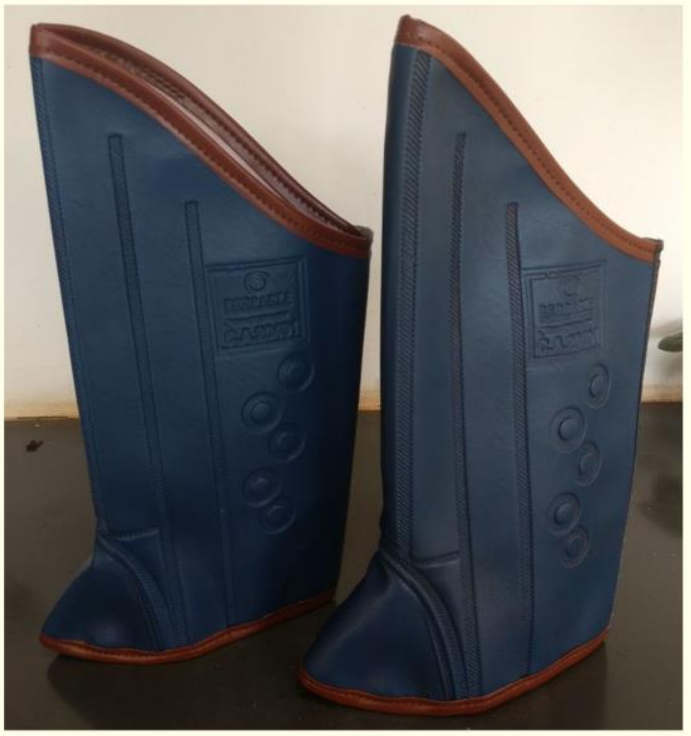

Fonte: Elaborado pelo autor (2018)

A perneira/caneleira é confeccionada geralmente em bidim com 3 talas. Sua finalidade é a proteção dos membros inferiores de picadas de animais peçonhentos, como por exemplo: aranhas, cobras e escorpiões.

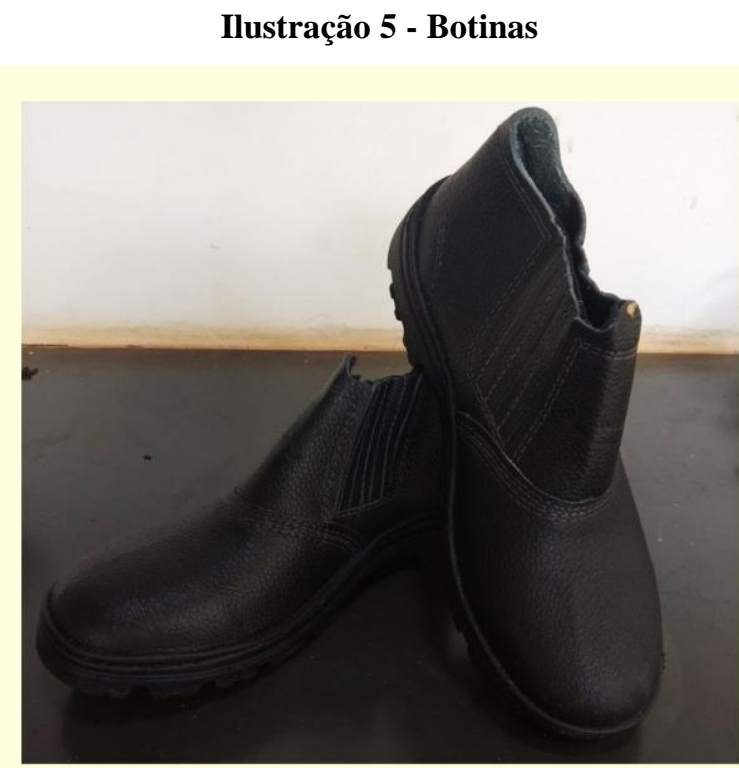

Fonte: Elaborado pelo autor (2018) 


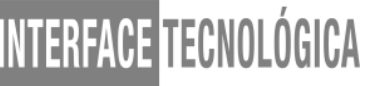

As botinas são confeccionadas geralmente em couro vacum, palmilha de montagem em couro no sistema strobel, solado de poliuretano monodensidade, sem bico de aço. Sua finalidade é a proteção dos pés contra pancadas e picadas de animais peçonhentos.

Ilustração 6 - Luvas de malha pigmentada

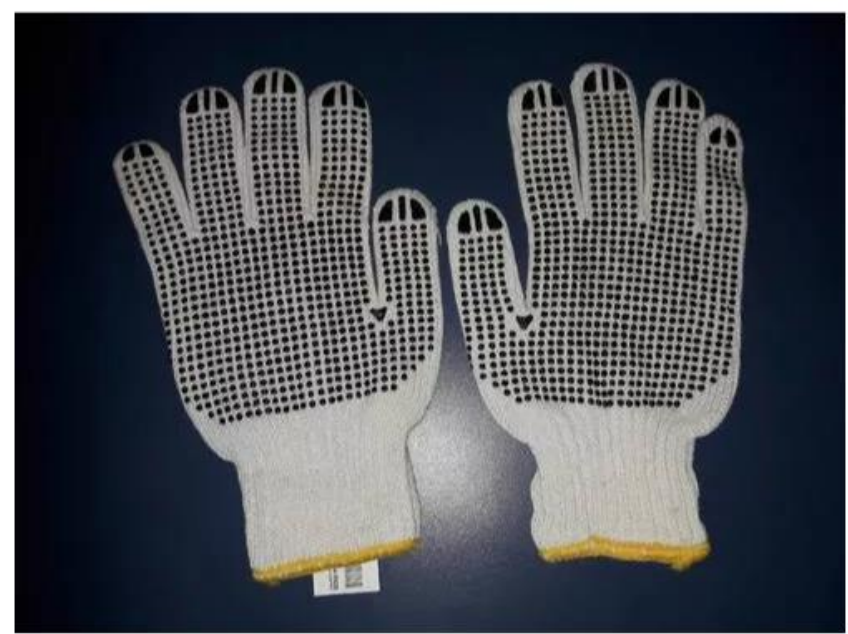

Fonte: Elaborado pelo autor (2018)

As luvas são confeccionadas geralmente de malha pigmentada fabricadas em fios de algodão e poliéster. As palmas revestidas com pigmentos de PVC, para maior aderência. Sua finalidade é a proteção das mãos contra espinhos, sujeiras e picadas de amimais peçonhentos.

Com a colocação de todos os EPIs, o trabalhador estará seguro a iniciar o trabalho da colheita. No final da colocação o funcionário deverá estar trajado da seguinte maneira: 


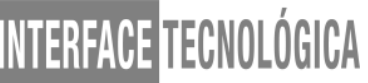

\section{Ilustração 7 - Colhedores com os EPI's completos}

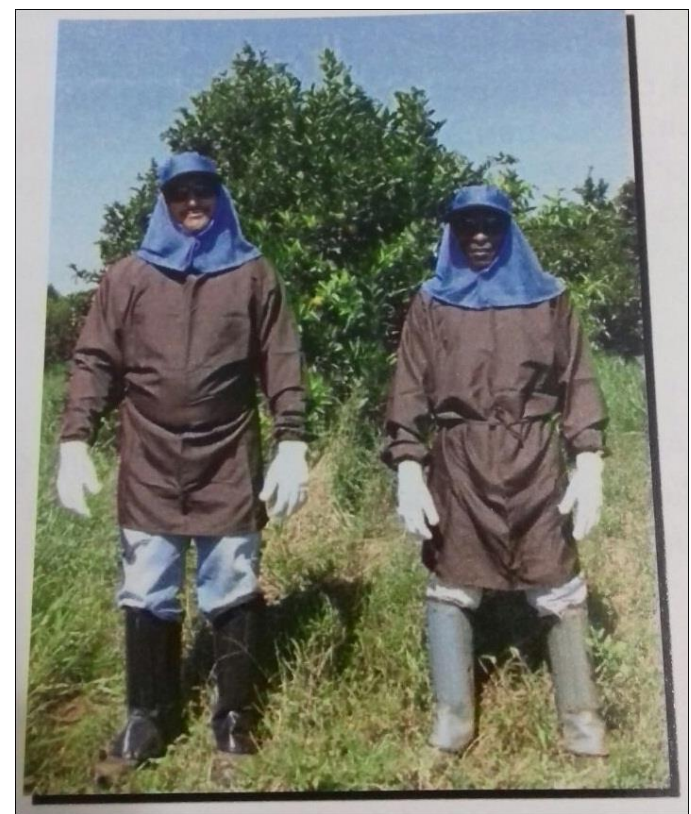

Fonte: Bussadori (2009)

Segundo a NR 31(2005), todo empregador deve assegurar que se forneçam aos trabalhadores instruções compreensíveis em matéria de segurança e saúde, bem como toda orientação e supervisão necessárias ao trabalho seguro.

Pois assim se entende que ao fornecer o EPI ao trabalhador o empregador deve dar o treinamento devido para o uso, limpeza e conservação desses equipamentos. Em caso de equipamento danificado deve-se comunicar imediatamente o empregador para fazer a manutenção ou até mesmo a substituição por um novo EPI.

\section{RESULTADOS E DISCUSSÃO}

Com a grande participação do Brasil na exportação de citrus, cada vez mais a produtividade dos colhedores deve ser intensificada, entretanto, a preocupação com a segurança dos trabalhadores deve ser colocada em primeiro lugar, para que não aconteçam acidentes e nem doenças ocupacionais.

Entre os principais resultados estão o fato de que os trabalhadores são a peça motriz de uma cadeia produtiva, sendo também a chave do progresso ou fracasso do empregador, então, existe a necessidade do investimento na prevenção de acidentes. Com isso os empregadores 


\section{WNEREFGEETECHOLOGGCA}

conscientes dessa temática vêm adotando medidas preventivas por meio de aquisições de EPI's e treinamentos para sua utilização.

Nascimento et al. (2009) destacam que o empregador tem algumas obrigações quanto aos EPI's que são fornecer gratuitamente ao empregado o tipo adequado de EPI para atividade que desenvolve; fornecer ao empregado somente EPI's com Certificado de Aprovação (CA); treinar o trabalhador sobre seu uso adequado; tornar obrigatório o seu uso; substituí-lo, imediatamente, quando danificado ou extraviado; responsabilizar- se pela sua higienização e manutenção periódica e comunicar ao Ministério do Trabalho qualquer irregularidade observada nos EPI's.

Esses equipamentos têm a finalidade de proteger o trabalhador dos riscos à sua saúde $\mathrm{e}$ segurança individual, porém devem ser empregados somente após a comprovação da impossibilidade de adoção de medidas de proteção coletiva. Apesar de existir inúmeros riscos, a falta de utilização dos EPIs continua sendo um dos principais fatores que causam agravamentos nos acidentes de trabalho referente à colheita manual de citrus.

\section{CONSIDERAÇÕES FINAIS}

Trata-se portanto, de uma obrigação legal do empregador fornecer o Equipamento de Proteção Individual, assim como do empregado de utilizá-lo. A utilização do EPI torna o ambiente de trabalho mais seguro e saudável, evitando assim situações de perigo que possam colocar a relação de trabalho em risco. O fornecimento, orientação, utilização e a fiscalização é de fundamental importância para a conscientização dos funcionários.

Sem o uso do EPI os funcionarios estão suscetíveis a se acidentar, podendo invalidar suas atividades funcionais e na pior das hipóteses vir a óbito.

$\mathrm{O}$ acidente de trabalho representa um custo elevado ao empregador. Ao investir capital na prevenção de acidentes, economiza-se com problemas secundários provenientes do acidente causado pela ausência do EPI, como por exemplo, os tratamentos médicos e as idenizações.

Vale a pena ressaltar que os EPIs não evitam acidentes, eles apenas o reduzem consideravelmente. Sendo assim o colhedor deve sempre manter-se trabalhando com atenção e muito cuidado, sempre tendo precaução com os atos inseguros. 


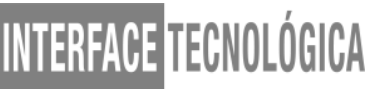

\section{REFERÊNCIAS}

BRASIL. Portaria GM n. ${ }^{\circ}$ 3.214, de 08 de junho de 1978. NR 6 - Equipamento de Proteção Individual - EPI. Diário Oficial da União. Brasília, 06 jul 1978.

BRASIL. Portaria MTE n. ${ }^{\circ}$ 86, de 03 de março de 2005. NR 31 - Segurança e Saúde no Trabalho na Agricultura, Pecuária Silvicultura, Exploração Florestal e Aquicultura. Diário Oficial da União. Brasília, 04 de mar 2005.

BRASIL. Decreto Lei n. ${ }^{\circ}$ 5.452, de $1^{\circ}$ de Maio de 1943 (artigo 160). Aprova a Consolidação das Leis do Trabalho. Diário Oficial da União. Rio de Janeiro, 9 de ago 1943. Disponível em: <http://www.planalto.gov.br/ccivil_03/decreto-lei/Del5452.htm>. Acesso em: 31 de Outubro de 2017.

BRASIL. Decreto Lei n. ${ }^{\circ}$ 8.213, de 24 de Junho de 1991. Dispõe sobre os Planos de Benefícios da Previdência Social e dá outras providências. Diário Oficial da União. Brasília, 24 de Junho de 1991. Disponível em: < www.planalto.gov.br/ccivil_03/leis/18213cons.htm >. Acesso em: 25 de abr de 2018.

BUSSADORI, R. C. Cartilha: Colheita da Laranja - SENAR (Serviço Nacional de Aprendizagem Rural). São Paulo. 2009.

COSTA, Hertz Jacinto. Acidente do Trabalho na Atualidade. Porto Alegre, Síntese, 2003.

NASCIMENTO, A. M. A. et al. A Importância do Uso de Equipamentos de Proteção na Construção Civil. Escola Técnica Estadual Martin Luther King. São Paulo, Dezembro de 2009.

RAMOS, P. Análise do Programa de Prevenção de Acidentes - Quase Acidente - e a Viabilidade da Aplicação Direta na Construção Civil -Universidade do Extremo Sul Catarinense - UNESC, Criciúma, Dezembro de 2009. 